\title{
Forest structure and composition at fire edges of different ages: Evidence of persistent structural features on the landscape
}

\author{
Karen A. Harper ${ }^{\mathrm{a}, *}$, Pierre Drapeau ${ }^{\mathrm{a}}$, Daniel Lesieur ${ }^{\mathrm{a}}$, Yves Bergeron ${ }^{\mathrm{a}, \mathrm{b}}$ \\ ${ }^{a}$ Chaire industrielle CRSNG UQAT-UQAM en aménagement forestier durable, Centre d'Étude de la Forêt, Département des Sciences Biologiques, Université du Québec à Montréal, \\ Montréal, Québec H3C 3P8, Canada \\ ${ }^{\mathrm{b}}$ Institut de Recherche sur les Forêts, Université du Québec en Abitibi-Témiscamingue, Rouyn-Noranda, Québec J9X 5E4, Canada
}

\section{A R T I C L E I N F O}

\section{Article history:}

Received 30 October 2013

Received in revised form 2 December 2013

Accepted 7 December 2013

Available online 31 December 2013

\section{Keywords:}

Deadwood

Edge development

Edge influence

Fire edges

Structural development

\begin{abstract}
A B S T R A C T
Boreal forest landscapes are dynamic with stands in different stages of development following standreplacing disturbances such as fire and insect outbreaks. Forest edges are an important component of these heterogeneous landscapes but there have been few studies on intermediate-aged forest edges which are needed for a comprehensive perspective on the spatiotemporal dynamics of forest edges. We described the structure, composition and extent of edge influence at 13, 25 and 39-year old fire edges in black spruce boreal forest in northwestern Québec and northeastern Ontario to characterize their structural development and to assess effects of edge development on the understorey. Forest structure and understorey composition were sampled along transects perpendicular to edges of the fires. Edge influence was assessed using randomization tests. Black spruce forest was relatively unaffected by edge influence beyond $5 \mathrm{~m}$ into the forest at all ages of edges studied. Edge influence on the understorey was weak and not extensive at intermediate-aged edges with few consistent responses of individual species. Less decayed snags and logs at 13 and 25-year old edges peaked in abundance at or near the edge with values higher than in either adjacent ecosystem. Overall, intermediate-aged fire edges in black spruce forest showed little evidence of further changes in canopy structure with time. Structural development of these edges as well as the regeneration of the disturbed areas also resulted in reduced edge influence on the understorey. A new insight from our study is that intermediate-aged forest edges may contribute unique structural features to landscapes such as a reservoir of deadwood that may be important for wildlife species.
\end{abstract}

(c) 2013 Elsevier B.V. All rights reserved.

\section{Introduction}

Boreal forest landscapes are mosaics of forest stands in different stages of development following stand-replacing disturbances such as forest fires. An increased amount of edge habitat has long been recognized as an important consequence of fragmentation from forest harvesting (Harper et al., 2005) and natural fire edges have been studied more recently for their unique qualities (Harper et al., 2004; Larrivée et al., 2008; Braithwaite and Mallik, 2012). Edge influence on vegetation generally extends less far in boreal forests (up to $20 \mathrm{~m}$ ) compared to temperate and tropical forests (Harper et al., unpublished data). Complex fire boundaries create highly variable edges that may influence the structure and

Abbreviations: DEI, distance of edge influence; MEI, magnitude of edge influence; RTEI, randomization test of edge influence.

* Corresponding author. Present address: School for Resource and Environmental Studies, Dalhousie University, Halifax, Nova Scotia B3H 3J5, Canada. Tel.: +1 902 494 6355; fax: +1 9024943728 .

E-mail address: karen.harper@dal.ca (K.A. Harper). composition of the adjacent forest stand further into the forest creating a wider, more gradual transition zone (Harper et al., 2004; Larrivée et al., 2008). However, there remain few studies on intermediate-aged fire edges which are needed for a comprehensive perspective on the spatiotemporal dynamics of forest edges.

Edge structure changes over time, resulting in dynamic boundaries and subsequent effects on the adjacent plant communities. Successional processes at the forest side of created edges are driven by microclimatic effects and changes in resource availability, but usually in the absence of vegetation removal or soil disturbance. Tree mortality and regeneration are key processes in the development of created edges. At regenerating edges, edge influence is expected to decrease over time as the contrast between adjacent communities is reduced (Matlack, 1994; Harper and Macdonald, 2002), resulting in 'edge softening' (Harper et al., 2005). Changes in plant species composition occur as a result of this structural development at created edges such as an increase in the proportion of understorey species influenced by the edge over 16 years (Harper and Macdonald, 2002). 
We assessed the structure, composition and extent of edge influence at 13, 25 and 39-year old edges in black spruce boreal forest. Our objectives were: (1) to characterize the structure of intermediate-aged fire edges, particularly for deadwood, and (2) to assess the effects of edge development on understorey composition and diversity. We compared the results of the present study with those of young fire edges in the same study area (Harper et al., 2004). We hypothesized that the magnitude and distance of edge influence decrease over time as the adjacent forest stand regenerates, blocking out edge influence on light and wind. However, structural changes may continue due to wind effects and changes to the understorey may persist before the adjacent forest regenerates.

\section{Methods}

\subsection{Study sites}

Our study site was in black spruce boreal forest in the Abitibi region in northwestern Québec and in northeastern Ontario $\left(49^{\circ} 62^{\prime}\right.$ to $49^{\circ} 87^{\prime} \mathrm{N}, 79^{\circ} 00^{\prime}$ to $79^{\circ} 50^{\prime} \mathrm{W}$, Fig. 1$)$. The area is part of the the northern Clay Belt, a broad physiographic unit characterized by lacustrine deposits from the proglacial lakes Barlow and Objibway (Vincent and Hardy, 1977). The topography is relatively flat at an elevation of approximately $300 \mathrm{~m}$ asl. Soils are predominantly organic, with clay deposits and some till (Gauthier et al., 2000). According to a nearby weather station in La Sarre, Québec $\left(48^{\circ} 46^{\prime} \mathrm{N}\right.$; $79^{\circ} 06^{\prime} \mathrm{W}$; Environment Canada, 1993), mean annual temperature is $0.8{ }^{\circ} \mathrm{C}$, annual precipitation is $856 \mathrm{~mm}$, and there are 64 frost-free days. The forest mosaic in our study area is part of the Picea mariana-moss bioclimatic domain (Saucier et al., 1998). P. mariana (Mill.) BSP (black spruce) is dominant in stands of all ages on clay and organic sites, and in old stands on sand sites (Harper et al., 2002). Other tree species include Pinus banksiana Lamb., Abies balsamea (L.) Mill, Betula papyrifera Marsh., Populus tremuloides Michx., Populus balsamifera L. and Larix laricina (Du Roi) Koch. The region is characterized by large crown fires that kill most of the trees and aboveground vegetation (Bergeron et al.,
2002). All burned sites were naturally regenerated without any planting; we avoided areas that were salvage cut.

\subsection{Sampling design and data collection}

We established four transects each at edges of single 13, 25 and 39-year old fires (Fig. 1, Table 1). Sampling was conducted between June and August 2001; spring ephemerals are rare in black spruce forests. Transects were at least $100 \mathrm{~m}$ away from other transects, major forest openings and any salvage-cut burned areas. Because we required sites with no salvage cutting, the number of possible transect locations was very limited since most of the fires that were easily accessible were partially or entirely salvage cut. Therefore, we could not control for edge aspect which spanned a range of orientations. Likewise, very few intermediate-aged fires were available leading to only one fire sampled for each age. We accounted for this unavoidable imbalanced sampling design by limiting direct statistical comparisons among different edge ages. Edges were created in forests dominated by $P$. mariana $(>88 \%$ trees $P$. mariana) with some co-dominance by $A$. balsamea. All edges were located within stands of similar composition and structure; therefore, fire edges did not appear to be the result of pre-existing composition. Stand age, canopy cover and height varied among forest stands next to fire edges; averages for all transects at different edge ages were $50-62 \%$ for canopy cover and $10-15 \mathrm{~m}$ for height.

For each transect, we located plots at various distances from both sides of the edge to cover the full extent of the edge. Rectangular plots $20 \times 5 \mathrm{~m}$, length parallel to the forest edge, were centred at the following distances along each transect: $-50,-15$, $-5,0,5,10,20,40,60,100,150$ and $200 \mathrm{~m}$ from the edge into the adjacent forest (negative distances indicate the burned side of the edge). The plot at $0 \mathrm{~m}$ straddled the forest edge which was located at the edge of the continuous forest canopy; in this ecosystem, fire edges were distinct and easy to delineate. Plots were included on the disturbance side of the edge to encompass the entire transition zone since the extent of edge influence may only be found within the disturbed area. We used data collected at 100 , 150 and $200 \mathrm{~m}$ to characterize interior forest; however, five of

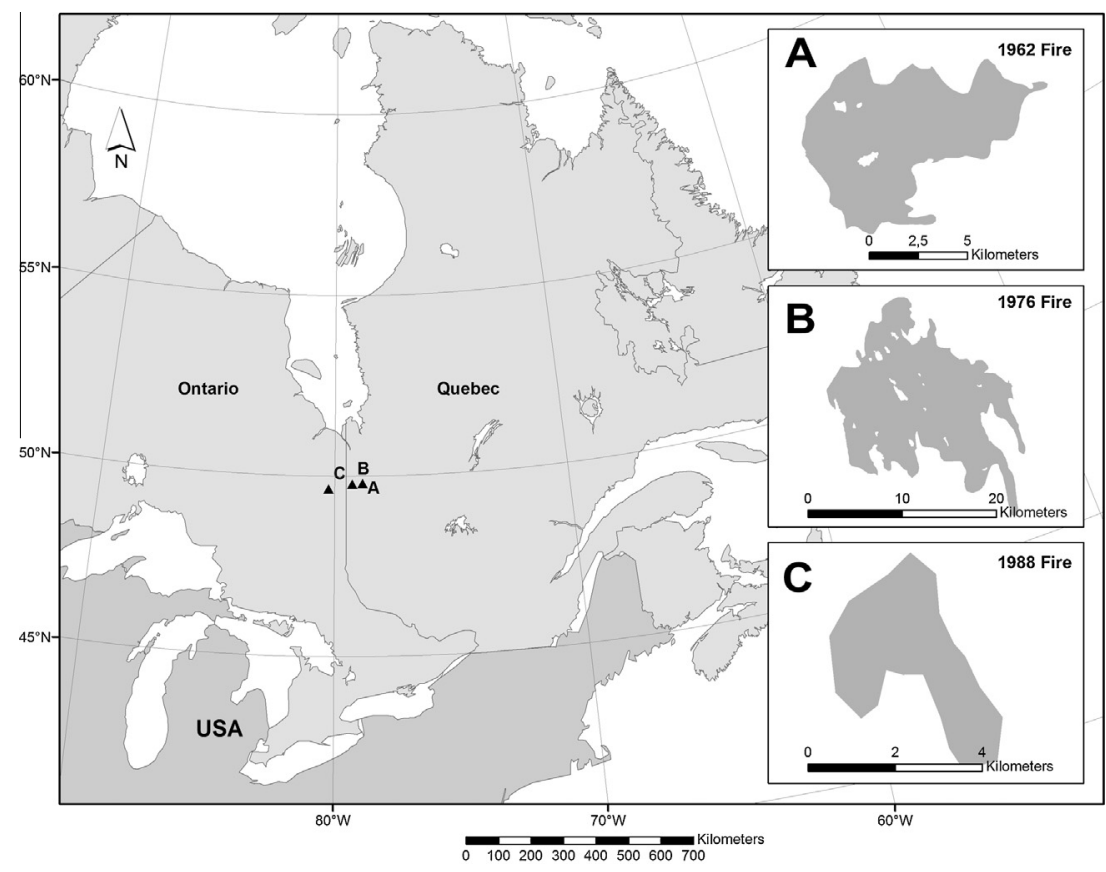

Fig. 1. Map showing the location of the study area and enlargements of the 1962 (A), 1988 (B) and 1976 (C) fires where edges were sampled. 
Table 1

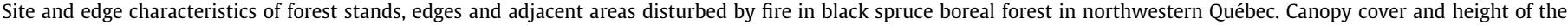
tallest trees were measured $60 \mathrm{~m}$ from the edge.

\begin{tabular}{|c|c|c|c|c|c|c|}
\hline Transect ID & Year of fire & Size (ha) of fire & Edge orientation $^{\mathrm{a}}$ & Age $^{\text {b }}$ (years) & Canopy cover (\%) & Height of the tallest tree $(\mathrm{m})$ \\
\hline Fire $A^{c}$ & 1988 & 918 & $90^{\circ}$ & $\mathrm{N} / \mathrm{A}$ & 44 & 12 \\
\hline Fire B & 1988 & 918 & $114^{\circ}$ & $\mathrm{N} / \mathrm{A}$ & 70 & 13 \\
\hline Fire C & 1988 & 918 & $220^{\circ}$ & $\mathrm{N} / \mathrm{A}$ & 66 & 12 \\
\hline Fire D & 1988 & 918 & $225^{\circ}$ & N/A & 69 & 24 \\
\hline Fire E & 1976 & 22,776 & $80^{\circ}$ & 1875 & 55 & 8 \\
\hline Fire $\mathrm{F}$ & 1976 & 22,776 & $115^{\circ}$ & 1875 & 34 & 10 \\
\hline Fire $\mathrm{G}^{\mathrm{d}, \mathrm{e}}$ & 1976 & 22,776 & $240^{\circ}$ & 1875 & N/A & 6 \\
\hline Fire $\mathrm{H}^{\mathrm{c}}$ & 1976 & 22,776 & $248^{\circ}$ & 1875 & 56 & 15 \\
\hline Fire I & 1962 & 5879 & $310^{\circ}$ & 1825 & 55 & 14 \\
\hline Fire $\mathrm{J}^{\mathrm{c}}$ & 1962 & 5879 & $314^{\circ}$ & 1825 & 16 & 10 \\
\hline Fire $K^{\mathrm{c}, \mathrm{d}, \mathrm{f}}$ & 1962 & 5879 & $355^{\circ}$ & 1775 & 75 & 14 \\
\hline Fire L & 1962 & 5879 & $360^{\circ}$ & 1775 & 71 & 16 \\
\hline
\end{tabular}

a Facing from the edge towards the forest.

b Data from a fire reconstruction map (Bergeron et al. 2004). The age of the forest stands surrounding the 1988 fire is unknown but is similar to the other forest stands.

c The $200 \mathrm{~m}$ plot could not be sampled due to proximity to another edge.

d $100 \mathrm{~m}$ plot could not be sampled due to proximity to another edge.

e Canopy cover measurements were not made.

f The $60 \mathrm{~m}$ plot was placed at $80 \mathrm{~m}$ to avoid a stream.

these plots could not be sampled (see Table 1 for details on exceptions to data collection). We were confident that $100 \mathrm{~m}$ was true interior forest since previous studies on edges in the same area found that edge influence only extended about $5 \mathrm{~m}$ into the forest (Harper et al., 2004). Two $2 \times 2 \mathrm{~m}$ shrub subplots and four $0.5 \times 0.5 \mathrm{~m}$ herb subplots were established systematically along the major axis of every plot (shrub and herb subplots at either end of the $20 \times 5 \mathrm{~m}$ plot, and herb subplots also $3 \mathrm{~m}$ from either side of the centre).

Trees ( $>5 \mathrm{~cm} \mathrm{dbh}$ ) and snags (standing dead trees $>5 \mathrm{~cm} \mathrm{dbh}$ and $>50 \mathrm{~cm}$ tall) were tallied in the $20 \times 5 \mathrm{~m}$ plots; the relative height of all trees and snags was estimated as dominant, co-dominant, intermediate or suppressed (Côté, 2000). We tallied the number of logs (downed coarse woody material) intersecting the major axis of the plot ( $>5 \mathrm{~cm}$ diameter at the intersection point). Decay stage was evaluated for all snags (classes 1-5, Thomas et al., 1979) and logs (classes 1-5, Maser et al., 1979). Canopy cover was measured at the centre of each plot using a convex spherical densiometer facing both directions of the transect. Height of the tallest tree was measured in the $60 \mathrm{~m}$ plots using a clinometer.

Within the shrub subplots, we estimated the cover for each shrub species ( $>50 \mathrm{~cm}$ tall) and for all shrub species combined, and we counted the number of seedlings $(<1 \mathrm{~m}$ tall), saplings established from layering ( $<1 \mathrm{~m}$ tall) and taller saplings ( $>1 \mathrm{~m}$ tall, $<5 \mathrm{~cm} \mathrm{dbh}$ ). Cover of all species of herbs, ground layer common mosses and macrolichens, and dwarf woody plants $(<50 \mathrm{~cm})$ was visually estimated within the herb subplots to the nearest $1 \%$ up to $5 \%$ and to the nearest $10 \%$ thereafter. Nomenclature follows Marie-Victorin (1995).

\subsection{Data analysis}

We assessed edge influence at fire edges for the following categories of response variables: overstorey structure (canopy cover, and tree, snag and log densities), understorey structure (total cover of shrubs, herbs, mosses and lichens), regeneration ( $P$. mariana layer, sapling and seedling densities) and cover of individual species (shrubs, herbs, mosses and lichens). Data from subplots were averaged for each plot. Diversity was calculated separately for shrubs, herbs, mosses and lichens using the Shannon index; calculations were made using cover values at the subplot level and then averaged for each plot. We also included structural diversity which we defined as the number and abundance of different combina- tions of height, dbh and decay stages of trees, snags and logs (c.f. Spies and Franklin, 1988) and calculated for each plot using the Shannon index. Separate analyses to assess edge influence on these response variables were performed for each age of fire edge ( $n=4$ transects each).

For each response variable, we calculated both the magnitude of edge influence (MEI) and the distance of edge influence (DEI). MEI is a measure of the strength of edge influence which we calculated as (Harper et al., 2005): $\mathrm{MEI}=\left(\bar{x}_{d}-\bar{x}_{i}\right) /\left(\bar{x}_{d}+\bar{x}_{i}\right)$; where $\bar{x}_{d}=$ average of a variable at distance $\mathrm{d}$ from the edge, and $\bar{x} i=$ average of a variable in interior forest (distances 100, 150 and $200 \mathrm{~m}$ from the edge).

To quantify DEI, we used the randomization test of edge influence (RTEI, Harper and Macdonald, 2011), which tests the significance of MEI for different distances from the edge using randomization tests of the data at a given distance from the edge and in the interior forest. When compared to other methods for determining DEI, RTEI was the only method that was generally invariable to sampling design while being sensitive to variation in the reference ecosystem but not at the edge (Harper and Macdonald, 2011). We used RTEI without blocking since one or two of the interior forest plots were missing along one of the transects and exact permutation (all possible permutations) since the sample size was low ( $n=4$ transects). All assessments of edge influence were done using the RTEI Add-In written by K.A. Harper in Microsoft Excel 2007 using VisualBasic (Microsoft Corporation, 2007) as introduced by Harper and Macdonald (2011). We used a $p$-value of 0.1 since we were primarily conducting exploratory analysis with limited sample size and therefore chose a less conservative approach in order to detect more trends. DEI was then estimated as the set of two or more consecutive distances (or separated by one distance) over which MEI was significant. We used this definition of DEI in order to counteract effects of multiple testing while still adopting a more liberal, exploratory approach to find possible trends.

\section{Results}

\subsection{Magnitude and distance of edge influence}

Overall, edge influence rarely extended beyond $5 \mathrm{~m}$ into the forest at intermediate-aged fire edges in black spruce boreal forest. Often the response variables were significantly different from 
interior forest only within the disturbed area with DEIs of -50 to $-5 \mathrm{~m}$ ( $5 \mathrm{~m}$ on the burned side of the edge). Therefore the edge transition zone was structurally and compositionally similar to interior forest. However, there were differences in some response variables and results varied among the different edge ages, revealing interesting trends in the structural development of fire edges.

Edge influence on forest structure was minimal at intermediateaged fire edges with no evidence of extensive damage to the tree canopy. For canopy cover, MEI and DEI were similar for all edge ages (Table 2). Tree density was only significantly lower right at the edge compared to interior forest; MEI at $0 \mathrm{~m}$ was variable for different edge ages. There were significantly more snags on the forest side of the edges of the 13-year old fire compared to interior forest (Table 2). Greater amounts of logs were found up to $5 \mathrm{~m}$ into the forest at the 13 and 25-year old fire edges compared to interior forest. There was no evidence of further change to the canopy at the fire edges since there was no consistent change in MEI or DEI for either canopy cover or tree density with edge age. Additionally, positive edge influence (greater values at the edge compared to the interior) on snag and log abundance had disappeared at the intermediate-aged fires where there was no significant edge influence on snag or log abundance.

Structural diversity on the forest side of the edge was generally similar to interior forest. Negative edge influence on tree structural diversity was limited to the burned area at all fire edges (Table 2). Results were similar for snag structural diversity for the 39-year old fire edges. MEI for snag structural diversity decreased with age of the fire edges. Edge influence on log structural diversity was positive or not significant (39-year old fire edges) and mostly confined to the disturbed area. At the 13 and 25-year old fire edges, DEI results indicate a peak in log structural diversity near the edge.

Change in the understorey was apparent at fire edges as evidenced by significant DEI of the cover of different types of plants, but there were few trends in species diversity or composition (Table 2). Total sapling density was significantly lower in the disturbed area compared to the interior forest at the 13-year old fire edges. Greater shrub cover was found up to $5 \mathrm{~m}$ on the disturbed and forest side of the edge at 13 and 25-year old edges, respectively. There was no significant edge influence on herb cover. Trends of lower moss cover in disturbed areas were often mirrored by greater litter cover (except at 13-year old fire edges) rather than lichen cover (except for greater lichen cover in 25-year old burned areas). MEI values for understorey structure varied with the greatest values often not significant, suggesting high variability within the interior forest. There was a decrease in MEI with age of fire edge for shrub cover but an increase for herb and litter cover. For species diversity, only lichen diversity had significant edge influence on the disturbed side of the 13-year old fire edges. Shrub diversity was lower at 25-year old fire edges but greater with a peak at the 39-year old fire edges.

\subsection{Patterns across the edge-to-interior gradient}

Patterns of deadwood abundance across the edge-to-interior gradient differed among different decay stages for different edge ages (Fig. 2, DEI results in Table 3). At the 13-year old fire edges (Fig. 2A), both recent and well-decayed snags had peaks in abundance near the edge. For logs, the pattern changed with greater decay stage, from a peak at the edge to a decrease from the burned area towards the forest to low abundance with no pattern. Likewise, there were three different patterns for snag abundance at the 25-year old fire edges (Fig. 2B): increase towards the forest, peak at the edge and decrease towards the forest (in order of increasing decay stage). Recent logs also showed a peak in abundance at the 25-year old fire edges whereas well-decayed logs were much more abundant within the burned area. Trends were less apparent at the oldest 39-year old fire edges with only a slight peak in abundance for the most decayed snags (Fig. 2C).

Trends in regeneration density were observed for different sizes of saplings and suppressed trees at different edge ages (Fig. 3, DEI results in Table 3). Peaks in seedling density occurred at the edges of 13 and 25-year old fires (Fig. 3A). Layering showed a slight peak just inside the forest at 13-year old fire edges but increased towards the forest at the 25-year old fire edges and showed no trend at the oldest fire edges (Fig. 3B). For taller saplings, there was a progression with age of fire edges of an increase, no trend, then a

Table 2

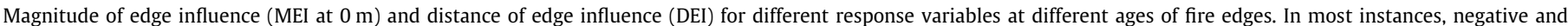

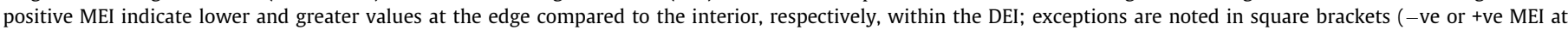

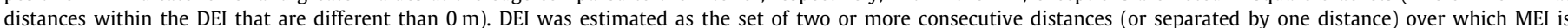
significant; negative values refer to distances within the disturbed area. Calculations of MEI and DEI are based on sample sizes of $n=4$ transects for each age of fire edge.

\begin{tabular}{|c|c|c|c|c|c|c|}
\hline & \multicolumn{2}{|c|}{ 13-year old fire } & \multicolumn{2}{|c|}{ 25-year old fire } & \multicolumn{2}{|c|}{ 39-year old fire } \\
\hline & MEI & $\mathrm{DEI}(\mathrm{m})$ & MEI & $\mathrm{DEI}(\mathrm{m})$ & MEI & $\mathrm{DEI}(\mathrm{m})$ \\
\hline \multicolumn{7}{|l|}{ Forest structure } \\
\hline Canopy cover & -0.22 & -50 to 0 & -0.22 & -50 to 0 & -0.19 & -50 to $-15,0$ \\
\hline Tree density & -0.10 & -50 to -5 & -0.46 & -50 to 0 & -0.07 & -50 to -5 \\
\hline Snag density & 0.10 & 15 to 25 & 0.22 & ns & -0.23 & ns \\
\hline Log density & 0.37 & -50 to 5 & 0.65 & -50 to 5 & -0.13 & ns \\
\hline Tree structural diversity & -0.05 & -50 to -5 & -0.25 & -50 to -5 & 0.02 & -50 to $-5[-$ ve $]$ \\
\hline Snag structural diversity & 0.22 & ns & 0.02 & ns & -0.39 & -15 to -5 \\
\hline Log structural diversity & 0.04 & $-5,5$ & 0.31 & -5 to 0 & -0.06 & ns \\
\hline \multicolumn{7}{|l|}{ Understorey } \\
\hline Total sapling density & 0.04 & -50 to $-5[-\mathrm{ve}]$ & 0.23 & ns & 0.07 & ns \\
\hline Shrub cover & 0.43 & -50 to -5 & 0.27 & -50 to 5 & -0.12 & ns \\
\hline Herb cover & -0.61 & ns & -0.24 & ns & 0.14 & ns \\
\hline Moss cover & -0.02 & -50 to -15 & -0.04 & -50 to $-5,5$ to 25 & -0.09 & -50 to -15 \\
\hline Lichen cover & 0.79 & ns & -0.41 & -50 to $-5[+\mathrm{ve}]$ & -0.30 & ns \\
\hline Litter & -0.14 & 25,60 & 0.33 & -50 to $-5,5,25$ & 0.74 & -50 to $-15,0$ \\
\hline \multicolumn{7}{|l|}{ Species diversity } \\
\hline Shrubs & 0.02 & ns & -0.06 & -50 to $-15,15,40$ to 60 & 0.14 & -5 to 5 \\
\hline Herbs & -0.61 & ns & 0.02 & ns & 0.10 & ns \\
\hline Mosses & 0.61 & ns & -0.10 & ns & 0.28 & ns \\
\hline Lichens & -0.13 & -50 to -15 & 0.25 & ns & 0.17 & ns \\
\hline
\end{tabular}

ns = no significant DEI. 
(A) 13 yr fire

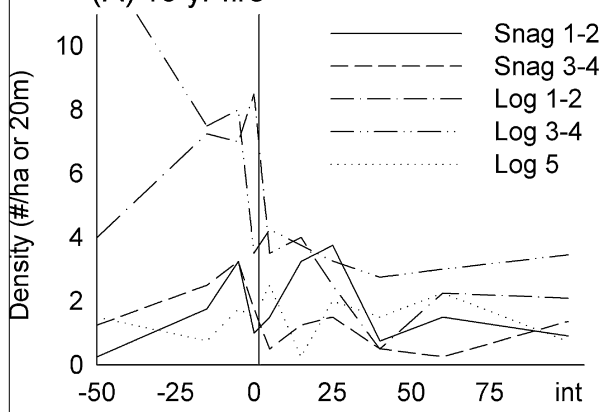

(B) $25 \mathrm{yr}$ fire

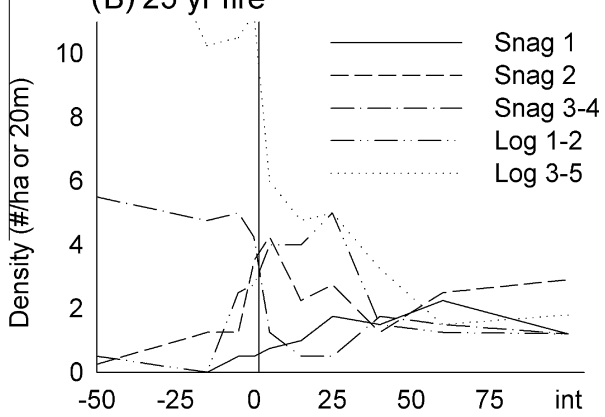

(C) $39 \mathrm{yr}$ fire

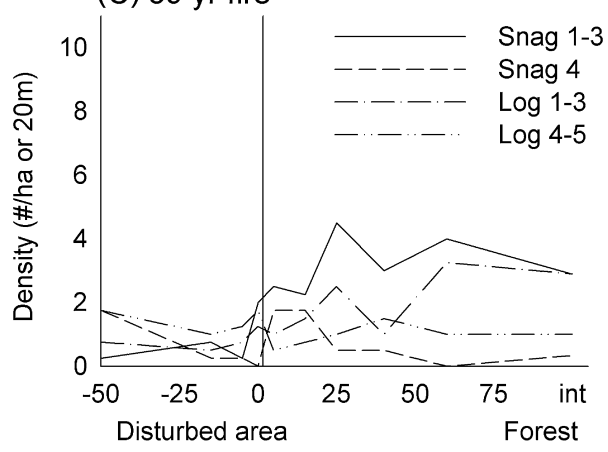

Distance from edge $(\mathrm{m})$

Fig. 2. Average density of snags and logs in different decay stages along the edgeto-interior gradient at (A) 13, (B) 25 and (C) 39-year old fire edges. The numbers in the legend refer to the decay stages. Snags and logs in consecutive decay stages with similar trends were grouped together for clarity; different categories were used for different edge ages. Sample sizes are $n=4$ transects for each age of fire edge. The average for interior forest (int) includes values at 100, 140 and $180 \mathrm{~m}$ from the edge. Note that the average values at $-50 \mathrm{~m}$ for logs in decay stages $3-4$ in A $(9.5$ per $20 \mathrm{~m}$ ) and for logs in decay stages $3-5$ in $B(17.8$ per $20 \mathrm{~m}$ ) are not visible on the graphs.

decrease towards the forest (Fig. 3C). There were few suppressed trees within the disturbed area except for 39-year old fire edges where there was a slight peak in density at the edge (Fig. 3D).

Overall, edge influence on individual species rarely $(<5 \%$ species) extended further than $5 \mathrm{~m}$ into the forest (Fig. 4). The youngest 13-year old fire edges had the greatest proportion of species affected by positive edge influence at all distances and by negative edge influence at distances within the forest. The trend in the proportion of species affected by edge influence was slightly more abrupt with a sharp decrease right at the edge for 39-year old fire edges compared to 25-year old edges for both positive and negative edge influence. Individual species hardly ever exhibited significant edge influence at more than one edge age at the edge (rather than just in the disturbed area, i.e. DEI beyond $-5 \mathrm{~m}$, Table 4). The only two exceptions were positive edge influence on Vaccinium angustifolium and negative edge influence on Carex sp. both at 13 and 25-year old fire edges. Other species were more (Cladonia spp., Polytrichum spp., Salix spp., Vaccinium myrtilloides) or less (Gaultheria hispidula, Rubus chamaemorus, Sphagnum spp.) abundant in the disturbed area compared to interior forest at more than one edge age, while Ledum groelandicum exhibited different responses to different disturbances. MEI increased with age of fire edges for Salix spp. and $R$. chamaemorus.

\section{Discussion}

A few decades after nearby disturbance, edges of black spruce forest stands remain relatively unaffected from forest fire. Edge influence rarely penetrated beyond $5 \mathrm{~m}$ into the forest, which was much lower DEI than reported for other forests in sub-boreal (40-120 m, Burton, 2002), temperate (16-137 m, Chen et al., 1992) and tropical (85-335 m, Laurance et al., 1998) regions. Although DEI estimates can vary widely depending on the method of analysis used (Harper and Macdonald, 2011), our results provide evidence that edge influence is substantially less in the boreal forest than in other forest ecosystems. Moreover, forest characteristics often extended into the burned area at these intermediateaged edges resulting in negative DEI estimates that were restricted to the disturbed areas away from the edge. Although the edge transition zone was structurally and compositionally similar to interior forest, differences in some response variables at and near the edge compared to interior forest illustrate the structural development of fire edges and effects on the understorey. Furthermore, patterns of some response variables, particularly different decay stages of deadwood, show how forest edges can provide a unique habitat on the landscape.

\subsection{Structural development of fire edges}

We found no evidence of continued change to the tree canopy with age of fire edges. The canopy may have even filled in; some structural change due to partial burning was noted up to $40 \mathrm{~m}$ into the forest at younger fire edges in the same study area (Harper et al., 2004). Unbroken snags found 15-25 $\mathrm{m}$ into the forest from 13-year old fire edges could be due to post-fire tree mortality, but they were suppressed trees and therefore their absence did not affect canopy cover. The lack of edge influence on total snags and logs at intermediate-aged fire edges also provides evidence against persistant structural change.

Fewer trees and more logs on the forest side of the edge, despite greater canopy cover, suggests that there may have been mortality but primarily of suppressed trees. However, windthrow or increased mortality due to edge influence has been observed in other forests (e.g., Chen et al., 1992; Laurance et al., 1998; Burton, 2002). Since black spruce trees are susceptible to windthrow (Lavoie et al., 2012), it may be the uneven structure of old-growth stands that results in their resistance to increased windthrow at their edges.

Regeneration of the dominant tree species is a common edge effect (Chen et al., 1992; Baker and Dillon, 2000; Burton, 2002; Harper and Macdonald, 2002) that affects the structural development of the edge. At fire edges in black spruce forest, more seedlings were found within the disturbed areas compared to interior forest at both 2-5-year old (Harper et al., 2004) and 13-year old fire edges (Fig. 3A). At intermediate-aged fire edges, peaks in seedling density suggest that seedling recruitment may still occur a couple of decades following edge creation. Greater recruitment in terms of understorey tree density was found at other edges (e.g., Baker and Dillon, 2000) but has only been compared with the adjacent undisturbed forest and not the disturbed area. More severe burning generally results in greater seedling germination, 
Table 3

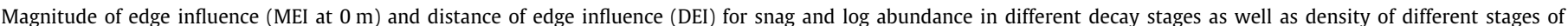

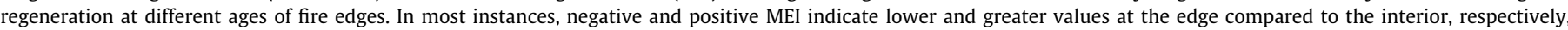

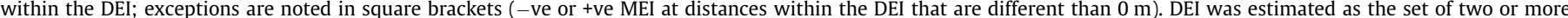

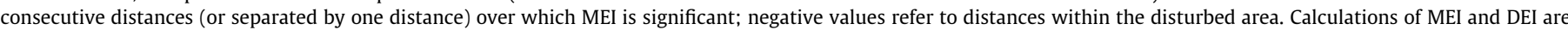
based on sample sizes of $n=4$ transects for each age of fire edge.

\begin{tabular}{|c|c|c|c|c|c|c|}
\hline & \multicolumn{2}{|c|}{13 year old fire } & \multicolumn{2}{|c|}{25 year old fire } & \multicolumn{2}{|c|}{39 year old fire } \\
\hline & MEI & $\mathrm{DEI}(\mathrm{m})$ & MEI & $\mathrm{DEI}(\mathrm{m})$ & MEI & $\mathrm{DEI}(\mathrm{m})$ \\
\hline \multicolumn{7}{|l|}{ Snag abundance } \\
\hline Decay stage 1 & -1.00 & ns & -0.41 & -50 to -15 & 0.10 & ns \\
\hline Decay stage 2 & 0.57 & 15 to 25 & 0.09 & -50 to $-5[-\mathrm{ve}]$ & -0.66 & -15 to -5 \\
\hline Decay stage 3 & -0.10 & ns & 0.56 & -50 to 0 & -0.28 & ns \\
\hline Decay stage 4 & 0.25 & ns & 0.58 & ns & -1.00 & ns \\
\hline \multicolumn{7}{|l|}{ Log abundance } \\
\hline Decay stage 1 & 0.75 & -5 to 0,15 & -1.00 & ns & -0.63 & ns \\
\hline Decay stage 2 & 0.47 & ns & 0.55 & 0 to 25 & -0.28 & ns \\
\hline Decay stage 3 & 0.03 & -50 to -5 & 0.67 & -50 to 0 & -0.28 & ns \\
\hline Decay stage 4 & -0.04 & ns & 0.75 & -50 to 0 & 0.23 & ns \\
\hline Decay stage 5 & 0.35 & ns & 0.80 & -15 to 0 & 0.38 & ns \\
\hline \multicolumn{7}{|c|}{ Regeneration density } \\
\hline Seedlings & 0.63 & ns & 0.94 & -50 to 0 & 0.32 & ns \\
\hline Layers & -0.17 & -50 to -15 & -0.36 & $-50,-5$ & 0.00 & ns \\
\hline Taller saplings & -0.42 & -50 to -5 & -0.04 & ns & 0.28 & -50 to $-15,0$ \\
\hline Suppressed trees & -0.21 & -50 to -5 & -0.58 & -50 to 0 & 0.00 & ns \\
\hline
\end{tabular}

ns = no significant DEI.

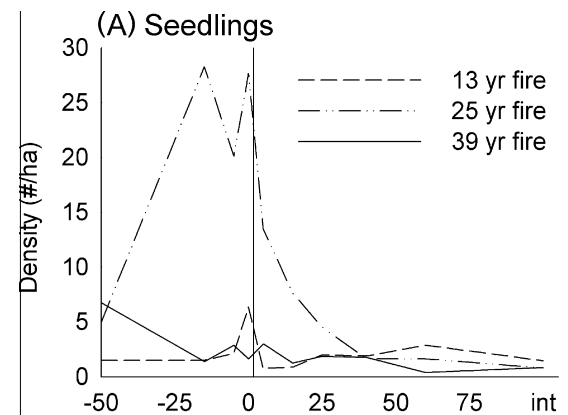

(C) Saplings

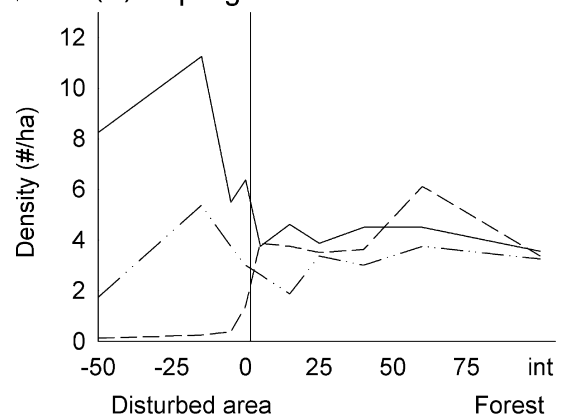

Distance from edge $(\mathrm{m})$
(B) Layers

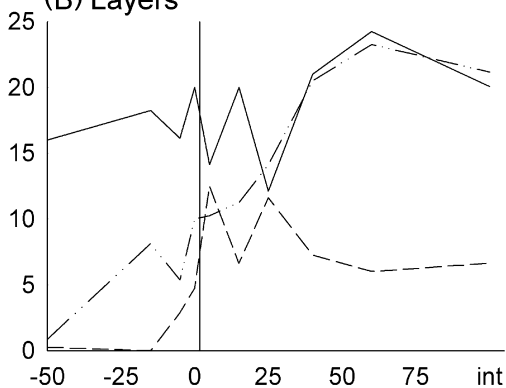

(D) Suppressed trees

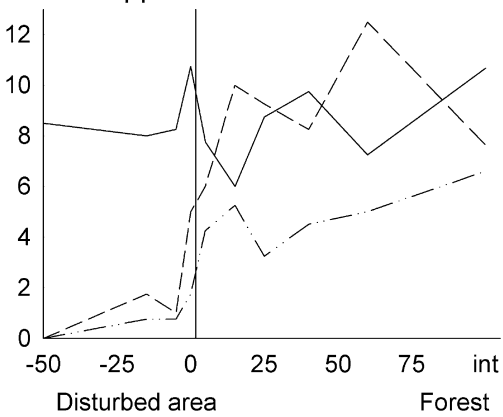

Distance from edge $(\mathrm{m})$

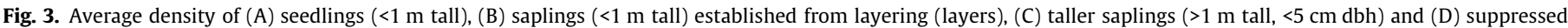

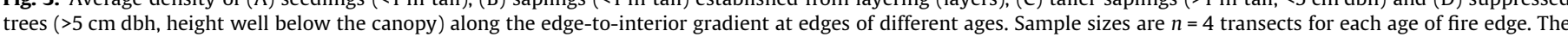
average for interior forest (int) includes values at 100,140 and $180 \mathrm{~m}$ from the edge. Note that the scale of the $y$-axis is different for each graph.

establishment and growth (Jayen et al., 2006; Kemball et al., 2006; Lecomte et al., 2006). Lighter severity would be expected at burn edges and would therefore have the 'worst seedbeds in the burn' (Greene et al., 2005), which is the opposite of our observed trend. Johnstone and Kasischke (2005) also found a decrease in black spruce regeneration with fire severity, but attributed it to competition with aspen which was not present at our forest edges. Greene et al. (2004) found that surviving Sphagnum in black spruce forests was one of the best seedbeds for black spruce and is concentrated in areas of lighter fire severity such as at fire edges. However, a persistent Sphagnum layer may hinder seedling establishment (Boudreault et al., 2002) or growth (Lavoie et al., 2007). Other possible explanations are that windthrow at the edge may have caused more uprooting or increased soil disturbance leading to better seedbed conditions (e.g., Esseen, 1994), or that seedlings regenerate at the edge of clearcuts from the seed rain from black spruce semi-serotinous cones in the adjacent intact forest (cf. Greene and Johnson, 1996, 2000). Although our sample sizes for 


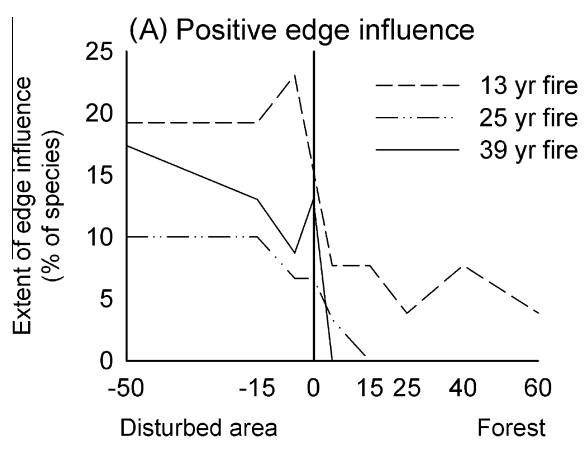

Distance from edge $(\mathrm{m})$
(B) Negative edge influence

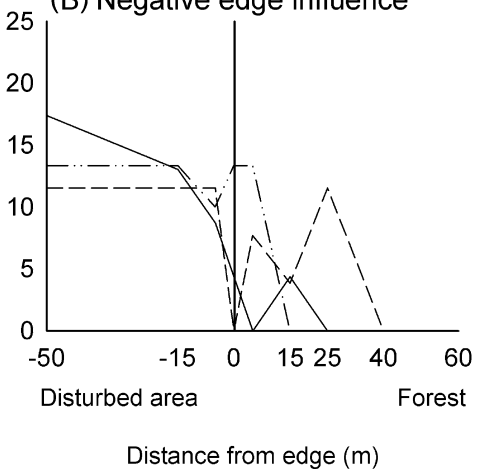

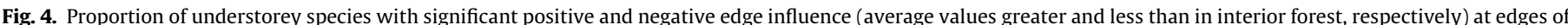

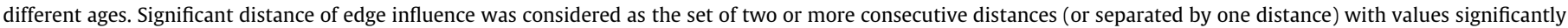

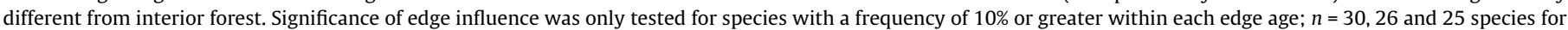
13, 25 and 39-year old fire edges respectively.

Table 4

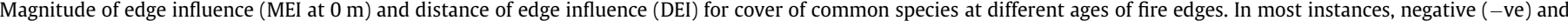

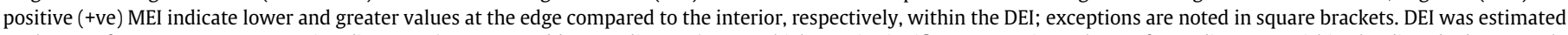

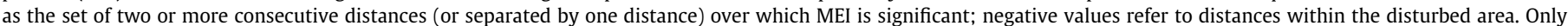

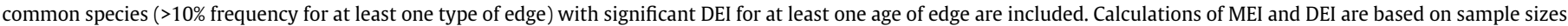
of $n=4$ transects for each age of fire edge.

\begin{tabular}{|c|c|c|c|c|c|c|}
\hline & \multicolumn{2}{|c|}{13 year old fire } & \multicolumn{2}{|c|}{25 year old fire } & \multicolumn{2}{|c|}{39 year old fire } \\
\hline & MEI & $\mathrm{DEI}(\mathrm{m})$ & MEI & $\mathrm{DEI}(\mathrm{m})$ & MEI & $\mathrm{DEI}(\mathrm{m})$ \\
\hline \multicolumn{7}{|c|}{ Cover of common shrub species } \\
\hline Chamaedaphne caliculata & $\mathrm{N} / \mathrm{A}$ & ns & -0.66 & 5,25 & -0.63 & ns \\
\hline Ledum groenlandicum & 0.58 & ns & 0.33 & -5 to 15,40 & -0.10 & ns \\
\hline Salix spp. & 0.10 & ns & 0.63 & ns & 1.00 & -50 to 5 \\
\hline Vaccinium angustifolium & 0.29 & $-50,-5,5$ & 0.80 & -50 to 25 & -0.45 & ns \\
\hline Vaccinium myrtilloides & 0.42 & -50 to 0 & -0.14 & ns & -0.15 & ns \\
\hline \multicolumn{7}{|c|}{ Cover of common herb species } \\
\hline Carex spp. & -1.00 & $-50,-5$ to 5 & -0.22 & 5,25 & -0.42 & ns \\
\hline Coptis groenlandica & -1.00 & -50 to $-15,0$ to 5 & $\mathrm{~N} / \mathrm{A}$ & ns & -0.02 & ns \\
\hline Cornus canadensis & -0.12 & ns & 0.47 & -5 to 0 & 0.17 & ns \\
\hline Gaultheria hispidula & -0.66 & -50 to -5 & 0.15 & ns & -0.54 & 50 to $-15,0$ \\
\hline Linnaea borealis & -1.00 & $-15,0$ to 5 & -1.00 & ns & 0.77 & ns \\
\hline Rubus chamaemorus & -1.00 & ns & -0.76 & -50 to 0,15 to 25 & -0.32 & ns \\
\hline Smilacina trifolia & -1.00 & ns & -0.21 & -50 to -5 & -0.38 & ns \\
\hline Vaccinium oxycoccos & -1.00 & ns & 0.25 & 40 to 60 & 0.18 & ns \\
\hline \multicolumn{7}{|c|}{ Cover of common moss species } \\
\hline Pleurozium schreberi & 0.18 & ns & 0.15 & ns & 0.19 & 5 to 15 \\
\hline Polytrichum spp. & 1.00 & -50 to -15 & 0.92 & -50 to 0 & $\mathrm{~N} / \mathrm{A}$ & ns \\
\hline Ptilium crista-castrensis & -0.95 & -50 to 5 & -1.00 & ns & 0.06 & ns \\
\hline Sphagnum spp. & -0.26 & ns & -0.10 & -50 to -5 & -0.52 & 0 to 25 \\
\hline \multicolumn{7}{|c|}{ Cover of common lichen species } \\
\hline Cladina mitis & 0.47 & ns & 1.00 & -50 to -5 & 0.51 & ns \\
\hline Cladina rangiferina & 0.18 & ns & -0.69 & -50 to $-5[+\mathrm{ve}]$ & -0.46 & ns \\
\hline Cladonia spp. & 0.32 & ns & 0.06 & -50 to -15 & 0.38 & ns \\
\hline
\end{tabular}

ns = no significant DEI.

$\mathrm{N} / \mathrm{A}=$ not applicable.

separate edge treatments are small, the peak in seedling density at the edges of both 13 and 25-year old fire edges suggests this may be a widespread phenomenon at fire edges, but still requires further testing.

The lack of a significant pattern across the edge for suppressed trees which had returned to forest interior levels within the burned area after 38 years may be due to self-thinning. At 16 -year old cut edges in deciduous boreal forest, a DEI of $20 \mathrm{~m}$ for suppressed trees (Harper and Macdonald, 2002) suggests that Populus spp. stems had grown into trees but had not yet completely self-thinned. Baker and Dillon (2000) hypothesized that there is a slower sealing of the edge in cooler climates resulting in greater mortality and disturbance at forest edges over a longer time period. We did not find evidence of this which may be due to regeneration within the disturbed area and/or more open canopied forest. Rather than developing a sidewall of vegetation found at maintained edges (Didham and Lawton, 1999; Harper et al., 2005), the forest grows within the disturbed area with little structural evidence of the boundary itself at these regenerating edges except for a slight peak in suppressed tree density that may disappear with time.

\subsection{Patterns of deadwood along the edge-to-interior gradient}

Our results show that patterns of deadwood across forest edges vary both spatially and temporally on the landscape. We found evidence of a peak in abundance of recently decayed deadwood at or 
near intermediate-aged forest edges in black spruce forest, an example of an 'interactive boundary' (Strayer et al., 2003) or an 'ecotonal effect' (Lidicker, 1999). The pattern was apparent for progressively greater decay stages for snags and logs at edges of fires of all three ages, which indicates that the trend continues with time. However, the pattern seemed to be receding at the oldest edges that we sampled which suggests the pattern may only last about four decades. The repetition of this pattern at different edges suggests it is likely to have emerged as a result of edge influence. Intermediate-aged edges appear to provide a different habitat in terms of decaying conditions for deadwood than the adjacent ecosystems, and may not be simply an intermediate transition zone. Although snags and logs generated by the fire had already decomposed after almost four decades (similar to Ferguson and Elkie, 2003 for snags), intermediate-aged edges appear to be a reservoir for deadwood on the black spruce boreal forest landscape in northwestern Québec.

A peak in deadwood abundance right at forest edges was first noted by Harper and Macdonald (2001) at lakeshore forest edges in deciduous boreal forest, a type of natural maintained edge where partial disturbance and greater productivity likely results in dynamic edges with more logs. In the same ecosystem, there was a greater abundance of logs at edges of 16-year old (but not 5 -year old) harvested areas compared to interior forest (Harper and Macdonald, 2002). However, sampling was not conducted on the other side of the edge so it is not known whether this was the same pattern with a peak at the edge. Angers et al. (2011) found delayed tree mortality and snag recruitment through time after low fire severity, which would be likely next to burn edges.

The pattern of greater amounts of less decayed deadwood across intermediate-aged forest edges could be explained by different decomposition rates or a lag in mortality following partial burning or windthrow. We propose the following hypotheses: (H1) decomposition is slower at edges compared to disturbed areas; (H2) partial burning (or other disturbance) causes additional mortality since edge creation; (H3) windthrow following edge creation creates additional deadwood at edges. According to the first hypothesis, the same amount of deadwood is created by the original disturbance throughout the disturbed area but decomposes slower near the edge than in the centre of the exposed disturbed area due to shading from the adjacent forest and consequently lower temperatures. Boulanger et al. (2011) found that severely burned snags decompose slower than lightly burned ones which contradicts our hypothesis; however, microclimate differences between the edge and the interior of the burned area and other factors might also be important. The other two hypotheses both state that a lag in mortality after edge creation (due to windthrow or partial disturbance) results in additional deadwood at later stages of edge development. There may also be a lag in windthrow of snags which may be more protected from wind at edges compared to the disturbed area and therefore remain standing longer. Snag density increased after 10-30 years within burned areas in a mixedwood boreal forest (Ferguson and Elkie, 2003). There was also greater tree mortality in forest fragments after a couple of decades resulting in greater deadwood abundance in a boreal forest in Norway (Jönsson et al., 2007). We can already reject $\mathrm{H} 3$ as the only possibility at fire edges since the phenomenon applies to snags as well as logs which would not be the case if windthrow was the only contributing factor. Further testing could include measurement of decomposition rates and explicitly looking at timing of mortality using long-term monitoring or dendrochronology (but see Angers et al., 2011).

If the phenomenon of greater undecayed deadwood at edges is found to be more widely applicable, forest edges could provide a reservoir of deadwood in the disturbance-prone boreal forest that may be very important for wildlife species that rely on transient recently burned areas. For example, Nappi and Drapeau (2009) found that the Black-backed woodpecker (Picoides arcticus), a fire specialist of the boreal forest, experienced high reproductive success for nests located near burned edges. These sites may offer better foraging conditions for woodpeckers since snags close to fire edges are less severely burned and thus more likely to support high densities of wood boring beetles (Saint-Germain et al., 2004a). Saint-Germain et al. (2004b) observed that the main prey of black-backed woodpeckers, the whitespotted sawyer (Monochamus scutellatus, Say), reached a higher abundance in burned areas with a higher percentage of unburned forest, thus indicating the importance of edges in forest mosaics of burned and unburned patches. Woodpeckers may therefore be able to stay longer at fire edges than within the burned area itself because of the persistence of recently-decayed snags at edges (Nappi et al., 2010). The pattern of deadwood across intermediate-aged edges thus shows how they can serve as a unique habitat type on the landscape.

\subsection{Understorey response to edge development at fire edges}

We found evidence at fire edges supporting our hypothesis that edge influence decreases following disturbance. Negative edge influence on shrub and moss cover at the forest edge decreased at fire edges (moss cover DEI and absolute value of MEI were greater at younger fire edges, Harper et al., 2004). This response was similar to the trend in shrub cover at cut edges in aspen forest (Harper and Macdonald, 2002). A decrease in the response of the understorey at edges following disturbance was perhaps most noticeable in the number of species with edge influence. Overall, it appears that in black spruce forest, responses of the understorey to edge creation are generally immediate and then decrease over time with regeneration of the adjacent forest. The absence of a lag or increase in edge influence may be related to the lack of further structural change at these same edges.

The general lack of edge influence for understorey species diversity right at the edge was similar to younger edges (Harper et al., 2004). An interesting exception of greater shrub diversity at the oldest fire edges we sampled is another example of a pattern with a peak in abundance right at the edge. This pattern could be due to a combination of shrub species from both habitats that persisted at these edges even with regeneration of the burned area. However, at 16-year old cut edges in aspen stands, there was significant edge influence for herb cover and richness but not shrub richness which was apparent at 5-year old cut edges (Harper and Macdonald, 2002). The edges we sampled showed little evidence of intrinsic ecotone properties regarding species composition including ecotonal species, exotic species or higher species richness (Lloyd et al., 2000).

Overall, there were few clear or consistent patterns of the response of species composition or individual species to edge influence over time, even when considering the younger fire edges (Harper et al., 2004), probably due to the open canopy and heterogeneity in the understorey of the black spruce forest. In a more closed-canopy deciduous boreal forest, there were differences in broad assemblages of understorey vegetation with varying levels of burn intensity (Lee et al., 2004). Following Roberts' (2004) factors in the response of the understorey to disturbance, vegetation at the edges of disturbed areas would be affected by competition with taller strata but not as much by microclimate which would be more of a factor within the disturbed area where much of the canopy is removed. Competition within the herb layer, damage to pre-existing plants and availability of propagules are also dominant factors where the understorey is undisturbed. Due to the open-canopied nature of black spruce forests, these factors are not very different from undisturbed interior forest. Likewise, indirect effects over time from effects of the canopy on the ground 
layer microclimate and edge structural development were likely minimal; there is little new regeneration when most of the understorey remains intact (Roberts, 2004). An exception to the general lack of edge influence on species composition was the different composition on the forest side of 39-year old fire edges which could indicate slow change in the understorey. However, due to the low sample size, further confirmation of these results is necessary to determine if this conclusion extends beyond this particular fire.

\section{Conclusions and implications}

Intermediate-aged fire edges in black spruce forest showed little evidence of further structural change with time; instead edges developed through further recruitment of seedlings and decomposition of deadwood. Structural development of these edges as well as the regeneration of the disturbed areas resulted in decreased edge influence on the understorey over time. Our results support the hypothesis that edge influence diminishes over time as patch contrast decreases at these regenerating edges (Harper et al., 2005).

The new insight from our study was the discovery of nonmonotonic patterns (peak at or near the edge) compared to both adjacent ecosystems (rather than simply an intermediate stage) indicating unique features of these intermediate-aged edges on the landscape. We found evidence for this pattern for snags and logs in progressively higher decay stages, as well as for seedling and sapling densities. Fire edges appear to provide a complex habitat and contribute unique structural features to the landscape. An important threat to biodiversity from forest management may be the loss of natural forest edges which could be conserved through large reserves and the reduction of salvage logging at edges which can affect edge structure and plant composition (Hanson and Stuart, 2005). The newly observed phenomenon at intermediateaged forest edges needs to be verified for different ecosystems and edge types, but shows promise as a unique feature of forest edges on the landscape. We suggest that further research (1) tests our hypotheses of different rates of decomposition or mortality due to windthrow in order to determine the mechanisms of edge influence, and (2) assesses the importance of this landscape feature for wildlife.

\section{Acknowledgements}

We are grateful for the field assistance of Vincent D'Aoust, Daniel Denis, Mélanie Lacroix, Mario Lafond and Samuel Pinna. Financial support was provided by a Natural Sciences and Engineering Research Council Discovery Grant to Harper, the Groupe de Recherche en Écologie Forestière, the Chaire Industrielle en Aménagement Forestier Durable, and the Sustainable Forest Management Network.

\section{References}

Angers, V.A., Gauthier, S., Drapeau, P., Jayen, K., Bergeron, Y, 2011. Tree mortality and snag dynamics in North American boreal tree species after a wildfire: long-term study. Int. J. Wildland Fire 20, 751-763.

Baker, W.L., Dillon, G.K., 2000. Plant and vegetation responses to edges in the southern Rocky Mountains. In: Knight, R.L., Smith, F.W., Buskirk, S.W., Romme, W.H. (Eds.), Forest Fragmentation in the Southern Rocky Mountains. University Press of Colorado, Boulder, pp. 221-245.

Bergeron, Y., Leduc, A., Harvey, B.D., Gauthier, S., 2002. Natural fire regime: a guide for sustainable management of the Canadian boreal forest. Silva Fenn. 36, 8195.

Bergeron, Y., Gauthier, S., Flannigan, M., Kafka, V., 2004. Fire regimes at the transition between mixedwood and coniferous boreal forest in northwestern Québec. Ecology 85, 1916-1932.
Boudreault, C., Bergeron, Y., Gauthier, S., Drapeau, P., 2002. Bryophyte and lichen communities in mature to old-growth stands in eastern boreal forests of Canada. Can. J. Forest Res. 32, 1080-1093.

Boulanger, Y., Sirois, L., Hebert, C., 2011. Fire severity as a determinant factor of the decomposition rate of fire-killed black spruce in the northern boreal forest. Can. J. Forest Res. 41, 370-379.

Braithwaite, N.T., Mallik, A.U., 2012. Edge effects of wildfire and riparian buffers along boreal forest streams. J. Appl. Ecol. 49, 192-201.

Burton, P., 2002. Effects of clearcut edges on trees in the sub-boreal spruce zone of northwest-central British Columbia. Silva Fenn. 36, 329-352.

Chen, J., Franklin, J.F., Spies, T.A., 1992. Vegetation responses to edge environments in old-growth Douglas-fir forests. Ecol. Appl. 2, 387-396.

Côté, M., 2000. Dictionnaire de la Foresterie. Dictionary of Forestry. Ordre des ingénieurs forestiers de Québec, Les Presses de l'Université Laval, Québec.

Didham, R.K., Lawton, J.H., 1999. Edge structure determines the magnitude of changes in microclimate and vegetation structure in tropical forest fragments. Biotropica 31, 17-30.

Environment Canada, 1993. Canadian climate normals 1961-1990. Canadian climate program. Atmospheric Environment Service, Downsview, Ontario.

Esseen, P.A., 1994. Tree mortality patterns after experimental fragmentation of an old-growth conifer forest. Biol. Conserv. 68, 19-28.

Ferguson, S.H., Elkie, P.C., 2003. Snag abundance 20, 30, and 40 years following fire and harvesting in boreal forests. Forestry Chron. 79, 541-549.

Gauthier, S., De Grandpré, L., Bergeron, Y., 2000. Differences in forest composition in two boreal forest ecoregions of Québec. J. Veg. Sci. 11, 781-790.

Greene, D.F., Johnson, E.A., 1996. Wind dispersal of seeds from a forest into a clearing. Ecology 77, 595-609.

Greene, D.F., Johnson, E.A., 2000. Tree recruitment from burn edges. Can. J. Forest Res. 30, 1264-1274.

Greene, D.F., Noel, J., Bergeron, Y., Rousseau, M., Gauthier, S., 2004. Recruitment of Picea mariana, Pinus banksiana, and Populus tremuloides across a burn severity gradient following wildfire in the southern boreal forest of Québec. Can. J. Forest Res. 34, 1845-1857.

Greene, D.F., Macdonald, S.E., Cumming, S., Swift, L., 2005. Seedbed variation from the interior through the edge of a large wildfire in Alberta. Can. J. Forest Res. 35, $1640-1647$.

Hanson, J.J., Stuart, J.D., 2005. Vegetation responses to natural and salvage logged fire edges in Douglas-fir/hardwood forests. Forest Ecol. Manage. 214, 266-278.

Harper, K.A., Macdonald, S.E., 2001. Structure and composition of riparian boreal forest: new methods for analyzing edge influence. Ecology 82, 649-659.

Harper, K.A., Macdonald, S.E., 2002. Structure and composition of edges next to regenerating clear-cuts in the boreal forest. J. Veg. Sci. 13, 535-546.

Harper, K.A., Macdonald, S.E., 2011. Quantifying distance of edge influence: a comparison of methods and a new randomization method. Ecosphere 2, art94.

Harper, K.A., Bergeron, Y., Gauthier, S., Drapeau, P., 2002. Post-fire development of canopy structure and composition in black spruce forests of Abitibi, Québec: a landscape scale study. Silva Fenn. 36, 249-263.

Harper, K.A., Lesieur, D., Bergeron, Y., Drapeau, P., 2004. Forest structure and composition at young fire and cut edges in black spruce boreal forest. Can. J. Forest Res. 34, 289-302.

Harper, K.A., Macdonald, S.E., Burton, P.J., Chen, J.Q., Brosofske, K.D., Saunders, S.C., Euskirchen, E.S., Roberts, D., Jaiteh, M.S., Esseen, P.A., 2005. Edge influence on forest structure and composition in fragmented landscapes. Conserv. Biol. 19, $768-782$.

Jayen, K., Leduc, A., Bergeron, Y., 2006. Effect of fire severity on regeneration success in the boreal forest of northwest Québec, Canada. Ecoscience 13, 143-151.

Johnstone, J.F., Kasischke, E.S., 2005. Stand-level effects of soil burn severity on postfire regeneration in a recently burned black spruce forest. Can. J. Forest Res. $35,2151-2163$.

Jönsson, M.T., Fraver, S., Jönsson, B.G., Dynesius, M., Rydgard, M., Esseen, P.A., 2007. Eighteen years of tree mortality and structural change in an experimentally fragmented Norway spruce forest. Forest Ecol. Manage. 242, 306-313.

Kemball, K.J., Wang, G.G., Westwood, A.R., 2006. Are mineral soils exposed by severe wildfire better seedbeds for conifer regeneration? Can. J. Forest Res. 36, 19431950.

Larrivée, M., Drapeau, P., Fahrig, L., 2008. Edge effects created by wildfire and clearcutting on boreal forest ground-dwelling spiders. Forest Ecol. Manage. 255, $1434-1445$

Laurance, W.F., Ferreira, L.V., Rankin-de Merona, J.M., Laurance, S.G., 1998. Rain forest fragmentation and the dynamics of Amazonian tree communities. Ecology 79, 2032-2040.

Lavoie, M., Paré, D., Bergeron, Y., 2007. Quality of growth substrates of postdisturbed lowland black spruce sites for black spruce (Picea mariana) seedling growth. New Forests 33, 207-216.

Lavoie, S., Ruel, J.-C., Bergeron, Y., Harvey, B.D., 2012. Windthrow after group and dispersed tree retention in eastern Canada. Forest Ecol. Manage. 269, 158-167.

Lecomte, N., Simard, M., Bergeron, Y., 2006. Effects of fire severity and initial tree composition on stand structural development in the coniferous boreal forest of northwestern Québec, Canada. Écoscience 13, 152-163.

Lee, P., Smyth, C., Boutin, S., 2004. Quantitative review of riparian buffer width guidelines from Canada and the United States. J. Environ. Manage. 70, 165-180.

Lidicker, W.Z., 1999. Responses of mammals to habitat edges: an overview, Landscape Ecol. 14, 333-343. 
Lloyd, K.M., McQueen, A.A.M., Lee, B.J., Wilson, R.C.B., Walker, S., Wilson, J.B., 2000. Evidence on ecotone concepts from switch, environmental and anthropogenic ecotones. J. Veg. Sci. 11, 903-910.

Marie-Victorin, Frère., 1995. Flore Laurentienne. 3e éd., Les Presses de l'Université de Montréal, Montréal, Québec.

Maser, C., Anderson, R.G., Cromack, K.J., Williams, J.T., Martin, R.E., Thomas, J.W., 1979. Dead and down woody material. In: Thomas, J.W. (Ed.), Wildlife Habitats in Managed Forests: the Blue Mountains of Oregon and Washington U.S. Department of Agriculture Forest Service, pp. 78-95.

Matlack, G.R., 1994. Vegetation dynamics of the forest edge - trends in space and successional time. J. Ecol. 82, 113-123.

Microsoft Corporation, 2007. Microsoft Office Excel.

Nappi, A., Drapeau, P., 2009. Reproductive success of the black-backed woodpecker (Picoides arcticus) in burned boreal forests: are burns source habitats? Biol. Conserv. 142, 1381-1391.

Nappi, A., Drapeau, P., Giroux, J.F., Savard, J.P.L., 2010. Effect of fire severity on longterm occupancy of saproxylic beetles and bark-foraging birds in burned boreal conifer forests. Int. J. Wildland Fire 19, 500-511.

Roberts, M.R., 2004. Response of the herbaceous layer to natural disturbance in North American forests. Can. J. Forest Bot. 82, 1273-1283.
Saint-Germain, M., Drapeau, P., Hebert, C., 2004a. Comparison of Coleoptera assemblages from a recently burned and unburned black spruce forests of northeastern North America. Biol. Conserv. 118, 583-592.

Saint-Germain, M., Drapeau, P., Hebert, C., 2004b. Landscape-scale habitat selection patterns of Monochamus Scutellatus (Coleoptera: Cerambycidae) in a recently burned black spruce forest. Environ. Entomol. 33, 1703-1710.

Saucier, J.-P., Bergeron, J.-F., Grondin, P., Robitaille, A., 1998. The land regions of southern Québec (3rd version): One element in the hierarchical land classification system developed by the Ministère des Ressources Naturelles du Québec. Internal Report, MRNQ, 21 pp.

Spies, T.A., Franklin, J.F., 1988. Old growth and forest dynamics in the Douglas-fir region of western Oregon and Washington. Nat. Areas J. 8, 190-201.

Strayer, D.L., Power, M.E., Fagan, W.F., Pickett, S.T.A., Belnap, J., 2003. A classification of ecological boundaries. BioScience 53, 723-729.

Thomas, J.W., Anderson, R.G., Maser, C., Bull, E.L., 1979. Snags. In: Thomas, J.W. (Ed.) Wildlife Habitats in Managed Forests: the Blue Mountains of Oregon and Washington U.S. Department of Agriculture Forest Service, pp. 60-77.

Vincent, J.S., Hardy, L., 1977. L'évolution et l'extinction des lacs glaciaire Barlow et Ojibway en territoire québécois. Géogr. Phys. Quat. 31, 357-372. 